Planta Med 2013; 79 - SL64

$\propto \square< \pm$ ה

DOI: $10.1055 / \mathrm{s}-0033-1351889$

\title{
Effects of saponin fractions from fenugreek and the soap bark tree in the diet on performance of Nile tilapia, Oreochromis niloticus (L.)
}

T Stadtlander $\underline{\mathbf{1}}$, WK Khalil $\underline{\mathbf{2}}$, B Levavi-Sivan $\underline{\mathbf{3}}$, Z Kerem $\underline{\mathbf{4}}$, H Dweik $\underline{\mathbf{5}}$, M Qutob $\underline{\mathbf{5}}$, S Abu-Lafi $\underline{\mathbf{6}}$, U Focken $\underline{\mathbf{1}}, \mathrm{K}$ Becker $\underline{\mathbf{s}}$

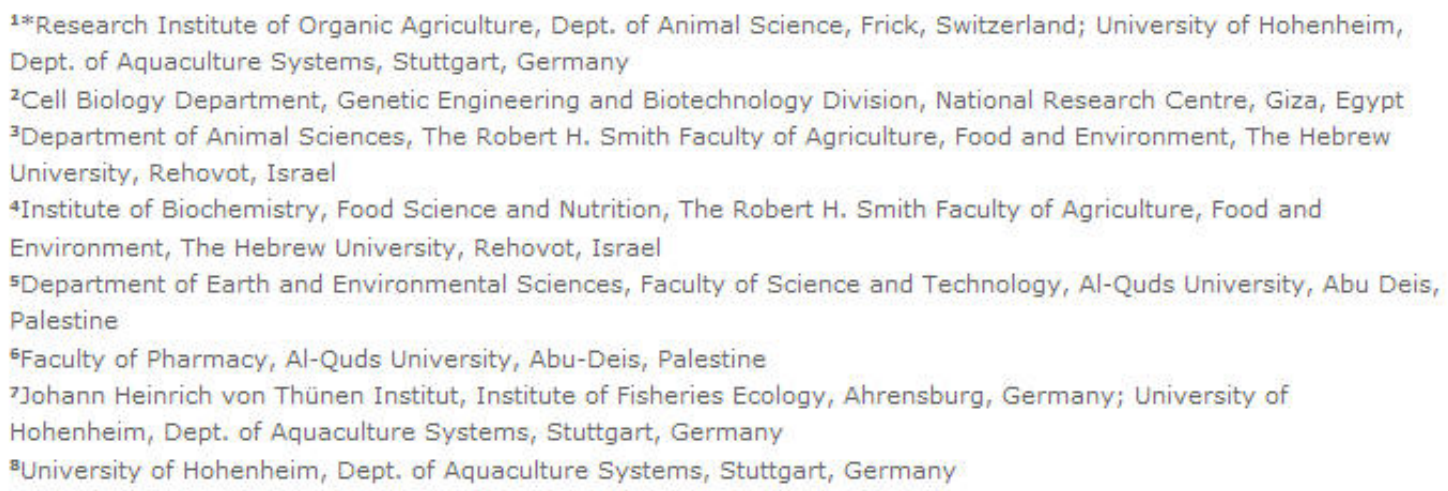

\section{Kongressbeitrag}

Saponins are generally regarded as anti-nutritional factors in aquaculture diets. However, previous experiments have shown that low dietary levels of saponins derived from Quillaja saponaria Molina do have growth promoting effects on common carp and Nile tilapia. Based on these experiments, we conducted an experiment in which we fed eluated saponin fractions from Q. saponaria and Trigonella foenum-graecum $\mathrm{L}$. (fenugreek) to Nile tilapia in a respirometric system allowing for continuous measurement of oxygen consumption. Saponins were eluated with consecutive methanol/water concentrations $(\mathrm{v} / \mathrm{v}, 40 / 60,60 / 40$, $80 / 20$ ) resulting in three different eluates for each plant. Fractions chosen were the $80 \%$ methanol eluate from Q. saponaria (80QS) and all three eluates from $T$. foenum-graecum (40TS, 60TS and 80TS). Three fish each were fed with low levels ( $150 \mathrm{mg} \mathrm{kg}^{-1}$ diet) of saponins in the diet and a control diet without saponins. Growth, feed and nutrient utilization, proximate composition, oxygen consumption and metabolic performance were evaluated.

The fish grew between $224 \%$ (40TS) and $266 \%$ (Control) over the eight week period. Feed conversion ratios were between 0.94 (80TS) and 1.15 (40TS) and protein efficiency ratios between 2.54 (80TS) and 2.16 (40TS). Due to low sample sizes, no statistical differences were found between control fish and saponin fed fish. However, numerically one of the tested saponin fractions (40TS) showed inferior performance (Table 1).

It is concluded that the tested saponins in the tested concentrations are no potential growth promoter for Nile tilapia. On the contrary, one fraction appears to be a growth inhibitor. 